\title{
MECHANISMS OF SETTING AND SHRINKPROOFING OF WOOL
}

\begin{abstract}
CETTING and shrinkproofing were the subjects of Wool $S$ Research Colloquium No. 4, held on October 17 at the new laboratories of the Division of Protein Chemistry, Commonwealth Scientific and Industrial Research Organization, in Melbourne, and attended by more than seventy delegates. The main emphasis of the colloquium was on mechanisms, both physical and chemical, rather than on practical aspects.

The first of the six speakers, Dr. J. Delmenico, discussed the difficulties in objective measurements of the degree of permanent set in pleated, creased or flat-set fabrics. For both yarns and fabrics, Delmenico favoured 'extension' set, that is, tho proportion of extension which is retained when the set wool is relaxed in water at $75^{\circ}$ for $30 \mathrm{~min}$. These conditions were considered to be more realistic for predicting the performance of set fabries than the usual test with boiling water for $1 \mathrm{~h}$. Setting of fabrics stretched in one direction involves not only extension set, but also the setting of the accentuated yarn crimp induced by lateral contraction of the fabric; changes in fabric width therefore provide a measure of this 'crimp' set. Permanent set, expressed as the percentage of extension retainod after relaxation, was shown unexpectedly to pass through a minimum at 25 per cent extension. A similar degree of set was obtained at 5-10 per cent as at 50-60 per cent extension. This provides some justification for extrapolating results obtained in setting at high extensions to flat-setting and permanent creasing where fibre extensions are probably quite low.
\end{abstract}

Dr. S. J. Leach and Dr. B. Milligan described an investigation into the role of thiol groups in setting, using amperometric and radiometric methods of thiol and disulphide analysis. They demonstrated that wool could not be set when its free thiol groups had been destroyed, and showed that the acceleration of setting by reagents such as bisulphite was due to the production of extra thiol groups. It was suggested that thiol-disulphide interchange facilitates transformation of the original polypeptide structure to new molecular conformations. These conformations must be stabilized to achievo 'permanent' set, or relaxation may occur by a reversal of the interchange mechanism. As might be expected on this hypothesis, loss of set is much slower in acid solution than in water due to the inhibition of thiol-disulphide interchange. This interchange could be permanently prevented by blocking or oxidizing the thiol groups after setting. Reagents such as sodium iodate, hydrogen peroxide, iodoacetamide or mercurials were suitable, and permitted a reduction in the steaming time required to achieve a given degree of set. Analyses provided no evidence of cross-linking or linkage rebuilding during setting or after-treatment of set wool.

Mr. M. Feughelman postulated that setting of an extended wool fibre in boiling water causes a disruption of the microfibrillar regions, the setting strain influencing the fraction of regions affected, but the extent of their disorganization being determined by the time of setting. The changes in birefringence, swelling in water, X-ray pattern and stress-strain relationship, after setting for various times, were cited to support the hypothesis. These changes were recognizable after setting for only $2 \mathrm{~min}$, provided the fibres were extended beyond their Hookean region. Longitudinal swelling on immersion in water increases progressively from 1.2 to $6-8$ per cont for fibres held at increasing setting strains, indicating the introduction of disorganized components in the organized microfibrils. Recovery of set fibres occurs as a result of the force of retraction remaining in the fibre, which is opposed by bonds formed in equilibrium with the extended state and by chain entanglement in the newly disorganized regions. The recovery per decade of time (length recovery is linear with $\log$ time) at $100^{\circ}$ of a set fibre is much slower at $p H \mathrm{H}$ than in water. If, after partial release in acid, the fibre is returned to water, its recovery rate reverts to the normal value, indicating that the recovory mechanism has not been impaired by the acid. This suggests that sotting an extended fibre results in a new arrangement of disulphido bonds which, after relaxation, counterbalanee the inherent force of retraction.

The afternoon session on shrinkproofing was opened by Dr. B. J. Sweetman, who, in a joint paper with Dr. J. A. Maclaren, discussed various oxidative shrinkproofing methods, in particular treatment with permonosulphuric acid followed by sulphite or with peracetic acid/sulphite. Those peracids provide little shrink resistance unless the wool is afterwards treated with sulphite. They found a relationship between uptake of oxidant and decrease in disulphide content of the intact wool, consistent with the hypothesis that cystyl residues (CySSCy) are mainly oxidized to the thiolsulphinate (CySSOCy) and thiol. sulphonate (CySSO${ }_{2} \mathrm{Cy}$ ), with little disulphide fission. Treatment of the oxidized wool with sulphite was shown by radiochemical methods to cleave these partially oxidized cystyl residues. Since sulphite afforded no shrink resistance if the partially oxidized cystyl residues were first reduced back to disulphide with sodium borohydride, it follows that fission of disulphide bonds is essential for shrinkproofing treatments of this type.

Dr. J. H. Bradbury and Dr. G. E. Rogers described techniques for the separation of euticle-rich material from fibres, using either mechanical scrapers or ultrasonio vibration. Examination of this material separated from shrinkproofed fibres permits the detection of chemical changes confined to the fibre surface; these changes are usually too small to be observed when whole fibres are analysed. Using both light and electron microscopy, it was shown that modification of the scale structure always oceurs with degradative chemical treatments which confer shrink resistance. Resin deposition may also produce shrinkproofing, either by spot-welding fibres together, or by covering the scales with a thin adherent layor of polymer. Those two types of deposition ean now be distinguished by light microscopy, and it is found that a thin layer of polymer can be produced by polymerization of monomer, in the presence of wool, but not by treatment of wool with a solution or dispersion of polymer. Of nine resin treatments examined, five depended on scale-masking for their effectiveness, and the other four on spot-wolding. Of the two types, the former is preferable in that much smaller amounts of resin are required, and the treatment may be applied at any stage in processing, rather than to tho finished fabric.

Dr. J. R. McPhee spoke of the virtues of shrinkproofing by rosin deposition, rather than by chemical treatments which degrade wool. Unlike chomically shrinkproofed wools, resin-treated wools exhibit shrink resistance which is virtually independent of the $p \mathrm{H}$ or temperature of the washing liquors. The amount of resin required to produce a given degree of shrink resistance may in some cases bo markedly reduced if the wool is first extracted with ethanol, or treated with hydrogen peroxide, or with hypochlorite in acid solution. This effect has been asoribed to a cleaning or roughening of the fibre surface, thereby assisting the polymer to adhere more strongly. McPhee and Feldtman have shown that these treatments 
lower the interfacial tension at the wool-air surface, with resultant increase of the spreading coefficients of urea. formaldehyde, polyamide and acrylio polymers on the fibre. This leads to more uniform coverage of the surface scales, and hence improved shrink resistance. This approach might allow selection of a particular resin, coupled with a suitable pretreatment, so as to ensure good spreading, and therefore high shrink resistance.

Fornial contributions were made by Prof. M. Chaikin, Mr. G. F. Flanagan, Dr. G. Laxer and Dr. V. A. Williams during the vigorous discussions which followed the main papers.
In summing up, Dr. E. G. Carter, of the International Wool Secretariat, congratulated the speakers on their attempts to provide sound theoretical bases for setting and shrinkproofing processes. He stressed the need for developing more analytical methods, suoh as those described for thiol, disulphide and lanthionine, whioh might help in discriminating between alternative theories. The measure of agreement between various speakers was indicative of closer collaboration between physicists and chemists than was apparent during his first visit to Australia in 1955 .
S. J. LEACB Brian Mulligan

\section{MINING AND ENGINEERING GEOPHYSICS IN SCANDINAVIA}

$\mathrm{T}$ HE fourth Nordic Meeting for Mining and Engineering Geophysies was held in Trondheim, Norway, during January 6-8, 1964.

The meeting on January 6 was a joint meeting with the sixth Nordic Geological Winter Meeting. More than 200 geologists, geophysicists, and technicians attended this, while the attendance amounted to about 110 for the remaining days. The participants included about 45 Norwegians, 40 Swedes, 20 Finns, 4 Danes and 1 Icelander. The sessions were presided over by Dr. David Malmqvist, Boliden Mining Co., Sweden, chairman of the planning committee, while the practical arrangements were organized by Andreas Eriksen, mining engineer, Sydvaranger Mining Co., Oslo, chairman of the organizing committee.

The joint meeting opened with an address of welcome by Prof. A. Hofseth, Norwegian Technical Highschool, Trondheim, in which he emphasized the importance of co-operation between mining engineers, geologists and geophysicists. The technical programme began with geological papers and shifted gradually towards more geophysical fields.

C. O. Mathiesen (Norway) gave an account of the copperfield at Bidjovagge, Finmark (northern Norway). The geophysical investigation of this field was given four years ago by G. F. Sakshaug at the second Nordic Meeting for Mining Geophysies. Mathiesen presented a geological picture according to which the ore-body follows a folded anticline running north-south. The deposit is estimated to be $2 \cdot 2$ million tons and the richest part of the deposit contains $2 \cdot 3$ per cent copper and 0.032 ounce gold. Another geological paper dealing with a new promising nickel deposit in Nord-Hitura (eastern Finland) was presented by V. Yletynen (Finland). The ore consists of pentlandite, pyrrhotite and chalcopyrite. A geological survey of the iron-titanium deposit at Rausand (western Norway) was presented by H. P. Geis (Norway). The ore-body is always associated with lenses of amphibolite and has been followed for a distance of about $55 \mathrm{~km}$. Folding of the ore-body and the host rock has occurred in connexion with the Caledonian orogenesis. The ore consists of magnetite and ilmenite, the latter containing much hæmatite.

Scott Smithson (Norway) reported twice; first, he gave a paper dealing with geological and geophysical investiga. tions of Norwegian Precambrian granites. From gravimetric measurements the thicknesses of several granite masses have been computed. The range of $1-4 \mathrm{~km}$ for the thicknesses of Precambrian granites is very small compared with younger granites. In his second paper, Scott Smithson gave some preliminary results of gravity meas. urements over the Jotun nappes of the Caledonides. The measurements have been facilitated by helicopter trans. portation in order to locate stations where terrain effects are at a minimum. The Bouguer anomalies range from -70 to -80 mgals both north and south of the nappes and rise to a maximum of about $-30 \mathrm{mgals}$ in the centre of the nappes. The calculated total thickness of the nappes ranges from about 5 to $10 \mathrm{~km}$ depending on the density contrast. The latter value corresponds to a provisional density contrast of $0.12 \mathrm{~g} /$ c.c.

P. F. Trøften (Norway) described an investigation of recordings of ore finds in northern Norway. From 1895 up to recent times 1,680 localities have been reported. Trøften concluded that apparently all outcropping orebodies and boulders have been located by 'old-timo' prospectors. "The Aims and Means of Ore-prospecting", was the title of a paper given by G. Törnquist (Sweden). Once again emphasis was placed on the co-operation between geologists, geophysicists and mining engineers, especially with regard to interpretation and re-interpretation. An estimate of the probability for new ore-bodies and for gains was given.

Applications of geophysics to geological mapping were demonstrated in three papers. V. Marmo (Finland) outlined the procedure used by the Finnish Geological Survey, where aeromagnetic maps are used by field geologists, and he presented several examples. Giving examples from the iron provinces at Sør-Varanger in northern Norway and at Arendal in southern Norway, as well as from the anorthosite field at Egernsund (south-western Norway), Prof. J. Bugge (Norway) gave an account of the usefulness of aeromagnetic surveys. Finally, J. Eklund (Sweden) described air-borne radiometric surveying of potassium, thorium and uranium in application to geological mapping.

A series of more general topics was opened by $G$. Jelstrup (Norway), who gave a review of the gravimetric surveying of Norway; he was followed by R. Kjær (Norway), who dealt with geomagnetic mapping. Two papers concerned with seismology were presented by research workers from Bergen University (Norway). A. Kvale gave an account of the seismic measuroments across the Skagerrak indicating $\mathbf{4 0 0}$ metres of Quaternary sediments and 2,960 metres of triassic sediments and/or phyllite deposited on granite and gneiss. The depth of the Mohorovičić discontinuity is computed to be $30 \mathrm{~km}$. Aeromagnetic traverses along the Norwegian coast showed several positive anomalies. M. Sellevold reported a series of refraction seismic traverses in northern Norway. A thin layer with a velocity of $7 \cdot 4-7 \cdot 5 \mathrm{~km} / \mathrm{sec}$ was traced between the basaltic layer of about $6.5 \mathrm{~km} / \mathrm{sec}$ and the mantle of about $8.3 \mathrm{~km} / \mathrm{sec}$ on the $300-\mathrm{km}$ long traverse from Troms $\varnothing$ to Muinio as well as on the traverse from Vardø to Kirkenes. An analysis of the $P$-waves of the earthquake on December 15, 1962, near Bodø, revealed likewise a thin-layer velocity of $7 \cdot 47 \mathrm{~km} / \mathrm{sec}$. R. Ronstad (Norway) described an attempt to establish a Fennoscandian gravimetric map. Ore-deposits were plotted, geological structures indicated, and also determinations of the geological age given. This section of the meeting was rounded off by $\mathrm{H}$. Major (Norway), who presented preliminary results of the geothermal gradient for a selection of mines. In general the gradient amounted to $1^{\circ} \mathrm{C}$ per 50 metres. 